\title{
Diversificação de Sustento Rural a partir da Exploração do Turismo Rural: o caso da Rota das Salamarias, Marau, Rio Grande do Sul
}

\section{Diversification of Rural Livelihood exploring the Rural Tourism: the case of Salamarias Route, Marau, Rio Grande do Sul (Brazil)}

\author{
Ana Cláudia Machado Padilha ${ }^{1}$ \\ Anaise Dalla Corte ${ }^{2}$ \\ Marcelino de Souza ${ }^{3}$
}

\begin{abstract}
RESUMO - O turismo rural surge como uma das opções que contribuem para a ampliação das estratégias de sustento das famílias rurais. O objetivo da pesquisa foi identificar a estratégia de diversificação dos meios de vida de produtores rurais que exploram o turismo rural na Rota das Salamarias, localizada em Marau, no estado do Rio Grande do Sul, Brasil. A pesquisa foi qualitativa e descritiva e realizada com três proprietários de empreendimentos integrantes da rota mencionada. Como principal resultado da pesquisa observou-se que os motivos mencionados pelos pesquisados centram-se na ampliação das fontes de renda, estímulo para fazer parte da rota que se alia à valorização do empreendimento rural, continuidade do trabalho dos antepassados em consonância com a melhoria da qualidade de vida da unidade familiar. $\mathrm{Na}$ implementação da diversificação a partir da exploração do turismo, identificaram-se a exploração do capital natural, físico, humano social e financeiro. Os fatores que facilitam seu acesso foram a diversidade dos recursos naturais, as tradições familiares e a mão de obra disponível. E quanto aos fatores que dificultaram sua exploração, cita-se a fragilidade de apoio governamental para o turismo e a infraestrutura de acesso. Também se evidencia elementos que modificam o acesso às capitais e outros que interferem no seu acesso. Mesmo assim, o turismo no contexto estudado demanda, adicionalmente oferta de cursos de qualificação para o setor.
\end{abstract}

Palavras-chave: Turismo rural. Diversificação dos meios de vida. Desenvolvimento rural.

\footnotetext{
${ }^{1}$ Doutorado e Mestrado em Agronegócios pela Universidade Federal do Rio Grande do Sul (UFRGS). Graduada em Ciências Contábeis pela Universidade de Passo Fundo (UPF). Professora titular II da UPF. E-mail: anapadilha@upf.br

${ }^{2}$ Graduação em Administração pela Universidade de Passo Fundo (UPF). Caixa do Banco Cooperativo Sicredi. E-mail: anaisedallacorte@hotmail.com

${ }^{3}$ Doutorado em Engenharia Agrícola pela Universidade Estadual de Campinas (UNICAMP). Mestrado em Extensão Rural pela Universidade Federal de Santa Maria (UFSM). Graduação em Agronomia pela Universidade Estadual de Londrina (UEL). Professor titular da Faculdade de Ciências Econômicas da Universidade Federal do Rio Grande do Sul (UFRGS). E-mail: marcelino.souza@uol.com.br
} 


\begin{abstract}
The rural tourism emerges as one of the options which could contribute to the expansion of rural families' livelihood strategies. The aim of the research was to identify the livelihood diversification strategy of rural producers who exploit rural tourism in the Salamarias Route, located in Marau, State of Rio Grande do Sul, Brazil. The research was qualitative and descriptive and carried out with three owners of projects that are part of the mentioned route. As the main result of the research it was observed that the reasons mentioned by the owners were focused on the expansion of the income sources, motivation to be part of the route that combines with the valorization of the rural property, continuity of the ancestors work in line with the improvement of the family quality of life. In the implementation of diversification from the tourism exploitation, it was identified the exploitation of natural, physical, social and financial capital. The factors which facilitate the access were the diversity of the natural resources, the family traditions and the available labor. And as for the factors that hindered the tourism exploitation, it was mention the fragility of government support for tourism and the access infrastructure. It was also highlighted the elements that modify the access to the capitals and others that interfere in the access. Even so, the tourism in the studied context additionally offer of qualification courses for the sector.
\end{abstract}

Keywords: Rural tourism. Diversification of livelihood. Rural development. 


\section{INTRODUÇÃO}

O agronegócio é desafiado pelo crescente incremento da competitividade, a qual está ligada à melhoria do nível de informação, gestão profissional, integração de elos de cadeias produtivas, relações contratuais, inovação tecnológica e sustentabilidade. Esses são alguns dos elementos que pautam as discussões atuais em torno do tema. A degradação ambiental e a perda de competitividade resultantes do aumento da agricultura intensiva em capital (industrial) no mercado mundial de alimentos são aspectos que levam muitos pequenos agricultores a reduzirem a intensificação de seus processos de produção agrícola (WARREN, 2002). Assim nas áreas rurais, ainda dominadas pela agricultura, como é o caso nos países em desenvolvimento, emerge a diversificação rural como uma estratégia importante para diminuir a vulnerabilidade dos meios de subsistência, a fim de atender às mudanças externas (WALKER; SALT, 2006).

Como em outras partes do mundo, entretanto, os produtores agropecuários brasileiros têm a difícil tarefa de gerenciamento da produção, enfrentando fatores incontroláveis, como o clima, as pragas, as doenças, a sazonalidade da produção, o baixo preço dos produtos, a defasagem tecnológica, a produção em baixa escala, entre outros. Tudo isso leva a um comprometimento das estratégias de gestão da propriedade rural, além da perda de competitividade. Portanto, cada vez mais estes produtores rurais são desafiados a buscar alternativas de sustento rural. De modo geral, a estratégia adotada consiste em diversificar sua pauta de sustento de acordo com a disponibilidade dos recursos, de modo a garantir o autoconsumo, diminuir o risco e ampliar a renda familiar, mesmo que isso não signifique a melhor remuneração do capital investido e a maximização dos lucros.

A estratégia de diversificação de sustento rural ou dos meios de vida, insere-se como oportunidade a oferta do turismo rural. É possível identificar no meio rural produtos turísticos inovadores, indutores de desenvolvimento endógeno que proporcionam ao turista experiências criativas, com seu envolvimento e participação ativa nasatividades oferecidas pelas comunidades(OLIVEIRA; DINIS, 2018).

Como exemplo de iniciativas turísticas no meio rural, insere-se a Rota das Salamarias, localizada no município de Marau, estado do Rio Grade do Sul, fundada no ano de 2008 a partir da criação de uma associação entre proprietários rurais e empreendedores em turismo que passaram a discutir a implantação e a organização do 
turismo rural nas comunidades rurais de Nossa Senhora do Carmo, São Luiz da Mortandade e Taquari. A denominação surge a partir da vocação para produção do salame, produto típico da culinária italiana local que é produzido e comercializado aos turistas, que originou, inclusive, a Festa Nacional do Salame que ocorre anualmente no município.

Nesse contexto, julga-se pertinente pesquisar a estratégia de diversificação dos meios de vida de produtores rurais que exploram o turismo na Rota das Salamarias. A escolha empírica justifica-se em razão de ser uma rota turística em desenvolvimento, integrada por atores da agricultura familiar que buscam ampliar a sua pauta de sustento a partir da exploração do turismo, além de demonstrar contribuição para o desenvolvimento socioeconômico da região e divulgação do município no norte do estado do Rio Grande do Sul. Quanto à justificativa teórica, argumenta-se o potencial de replicação da estrutura teórica da estratégia de diversificação de sustento rural (ELLIS 1998, 2000; PADILHA, 2009; PADILHA et al., 2017; PADILHA et al., 2019) no contexto do turismo rural, que pode explicar a resiliência de famílias rurais no contexto competitivo contemporâneo. Por fim, uma discussão teórica a partir do objetivo proposto, elaborado com base em elementos interdisciplinares, revela-se como uma temática emergente que pode contribuir para o avanço dos estudos no campo do agronegócio envolvendo o turismo, conforme abordado a seguir.

\section{A ESTRATÉGIA DE DIVERSIFICAÇÃO DO SUSTENTO RURAL E O TURISMO RURAL}

Ao longo dos últimos anos muitas transformações no meio rural vêm acontecendo, principalmente quanto às atividades econômicas e ao uso de recursos naturais (RAMEH; SANTOS, 2011). Nesta perspectiva, a diversificação é geralmente reconhecida como uma importante estratégia para diminuir a vulnerabilidade de acesso aos meios de subsistência.

A diversificação de meios de vida é uma das características mais notáveis dos meios de subsistência rural (GAUTAM; ANDERSEN, 2016). Esta é definida como sendo "o processo pelo qual as famílias rurais constroem um portfólio diversificado de atividades e capacidades de apoio social para sobreviver e melhorar seu padrão de vida" (ELLIS, 1998, p.4). A diversificação é um hábito, uma vez que poucas pessoas coletam 
todos seus rendimentos de uma única fonte, concentrando sua riqueza na forma de um único bem ativo, ou aplicam seus ativos em somente uma (BARRETT; REARDON; WEBB, 2001). Ela também é uma estratégia cada vez mais relevante para os agricultores como resposta à redução da rentabilidade e às mudanças na agricultura tradicional (McNALLY, 2001).

Diante disto, parece coerente considerar que o produtor diversifica suas estratégias de sustento geralmente motivado pela disponibilidade e acesso aos recursos. Para Ellis (2000), o processo da estratégia de diversificação dos meios de vida é possível quando a família rural tem acesso aos capitais natural, humano, social, físico e financeiro. Isso parece complexo se realizada a leitura de que, em se tratando de famílias rurais que precisam produzir seu meio de sustento, o acesso aos recursos apresenta-se como um desafio ao se optar pela diversificação. Com base nisso, os trabalhos de Ellis (1998, 2000) tem contribuído na dimensão da pobreza rural, desenvolvimento econômico, políticas rurais, pressão econômica e conjuntural que alcança a exclusão social, uma vez que seu êxito depende do desenvolvimento de políticas públicas que contribuam em termos de viabilidade e consolidação.

Para investigar questões de vulnerabilidade e respostas das famílias às mudanças Zheng et al. (2014) empregaram a abordagem de meios de vida sustentável proposta por Scoones (1998). Essa abordagem se apoia na ênfase das capacidades das famílias rurais para combinar e implantar um conjunto de ativos viáveis às atividades de subsistência, denotando que a capacidade de implementar estratégias depende do contexto estabelecido que regula o acesso aos recursos específicos (ELLIS; BIGGS, 2001).

Dentre os motivos pelos quais as famílias rurais diversificam negócios rurais agropecuários em atividades não agropecuárias podem ser elencados o tempo de retorno do trabalho na terra, falhas do mercado (crédito), fricções (mobilidade ou entrada em nichos de alto retorno), administração de risco ex-ante e para lidar ex-post com os choques adversos (BARRETT, REARDON e WEBB, 2001).

Ellis (2000) considera as seguintes atividades relacionadas ao sustento das famílias rurais: (a) atividades baseadas em recursos naturais:compreende a coleta, cultivo de alimentos, cultivo de produtos não alimentares, pecuária e pastoreio, sendo que as atividades não rurais podem ser expressas pela produção de tijolos, tecelagem e pastagem; (b) atividades não baseadas em recursos naturais:relacionados com a venda de produtos rurais, insumos e bens de consumo, bem como aos outros serviços rurais, como 
a manutenção de equipamentos, manufaturas rurais, empregos formais e transferência de renda.

Mais do que isso, a composição deste portfólio tem relevância política, pois a situação de vulnerabilidade das famílias varia de acordo com a dependência que possuem de determinados ativos ou atividades (ELLIS, 2000). Para o autor, esse fato precisa ser considerado ao serem definidas políticas de incentivo direcionadas a determinadas atividades, bem como aquelas que afetam o acesso aos ativos. Com relação aos ativos, Ellis (2000) formula cinco categorias que compõem a denominada "plataforma de sustento de famílias rurais" (Quadro 1).

O contexto consiste em fatores exógenos (predominantemente tendências e choques em domínios biofísicos e socioeconômicos) e fatores endógenos (principalmente instituições e organizações que regem as normas e estruturas sociais internas que regulam o acesso aos recursos) (ELLIS, 2000).

No entendimento de Ellis (2000), o resultado da estratégia de diversificação de sustento poderá afetar a unidade familiar ou indivíduo em termos de segurança do sustento, estabilidade de renda, redução do impacto da sazonalidade das atividades produtivas sobre a renda familiar, entre outros. Contudo, a eficácia da estratégia de diversificação de sustento rural não depende somente dos ativos, uma vez que também está ligada à habilidade da família rural em transformar os ativos em renda, alimento, ou em outras necessidades básicas de forma eficaz (NIEHOF, 2004).

QUADRO 1: PLATAFORMA DE SUSTENTO DAS FAMÍLIAS RURAIS.

\begin{tabular}{|c|c|}
\hline CAPITAIS & ESPECIFICIDADES \\
\hline Natural & $\begin{array}{l}\text { Compreende a terra, a água e os recursos biológicos para gerar os meios de sobrevivência. } \\
\text { Não é estático e sua utilização para fins de sobrevivência não está restrita às atividades } \\
\text { como coleta e caça, podendo ser dividido em renováveis e não-renováveis que se } \\
\text { condicionam às questões geográficas. }\end{array}$ \\
\hline Físico & $\begin{array}{l}\text { Compreende o capital que é criado por meios de processos produtivos econômicos. } \\
\text { Máquinas, ferramentas, entre outros, são ativos físicos. Economicamente, é definido como } \\
\text { bem de produção. Quando servir como residência das famílias é considerada improdutivo. }\end{array}$ \\
\hline Humano & $\begin{array}{l}\text { Refere-se ao trabalho doméstico que é influenciado pela educação, habilidade e saúde, } \\
\text { incrementado pelo investimento em educação e treinamento, bem como pela } \\
\text { potencialização das habilidades que são adquiridas no desenvolvimento da atividade. }\end{array}$ \\
\hline $\begin{array}{l}\text { Financeiro } \\
\text { e seus } \\
\text { substitutos }\end{array}$ & $\begin{array}{l}\text { Compreende a liquidez que o grupo doméstico tem disponível para realizar suas } \\
\text { estratégias. É potencializado com o acesso à linha de crédito e não é visto diretamente } \\
\text { como forma produtiva de capital, mas pode converter-se em outras formas de capital ou ser } \\
\text { utilizado diretamente no consumo. }\end{array}$ \\
\hline Social & $\begin{array}{l}\text { São os vínculos do indivíduo e do grupo doméstico com a comunidade e os efeitos das } \\
\text { relações coma comunidade. Em sentido mais amplo, é a capacidade de inclusão social. }\end{array}$ \\
\hline
\end{tabular}

FONTE: Elaborado com base em Ellis (2000). 
Para fins de pesquisa, a Figura 1 apresenta uma sistematização dos principais elementos que norteiam a etapa empírica. Reportando-se à figura citada, assume-se que as famílias rurais apresentam motivações para a diversificação rural, particularmente no âmbito do turismo rural (ANNES; BESSIERE, 2018), podendo ser de natureza econômica ou social (McGEHEE; KIM; JENNINGS, 2007). A dimensão econômica é uma maneira de diversificar as atividades agrícolas, ampliando a renda cada vez menor (BUSBY; RENDLE, 2000; WEAVER; FENNELL, 1997), apesar de alguns teóricos mencionarem que os benefícios econômicos são frequentemente limitados (BUSBY; RENDLE, 2000). Além da lógica econômica, outros pesquisadores se concentram mais nas motivações sociais (e culturais). Conhecer pessoas, reduzir o isolamento social, mas também educar e compartilhar seu conhecimento e paixão, ou mesmo promover o patrimônio arquitetônico local, são todos mencionados pelos empreendedores do agroturismo (DUBOIS; SCHMITZ, 2015; NICKERSON; BLACK; McCOOL, 2001; WEAVER; FENNELL, 1997; WRIGHT; ANNES, 2014).

FIGURA 1: ESTRATÉGIA DE DIVERSIFICAÇÃO DOS MEIOS DE VIDA A PARTIR DA EXPLORAÇÃO DO TURISMO RURAL

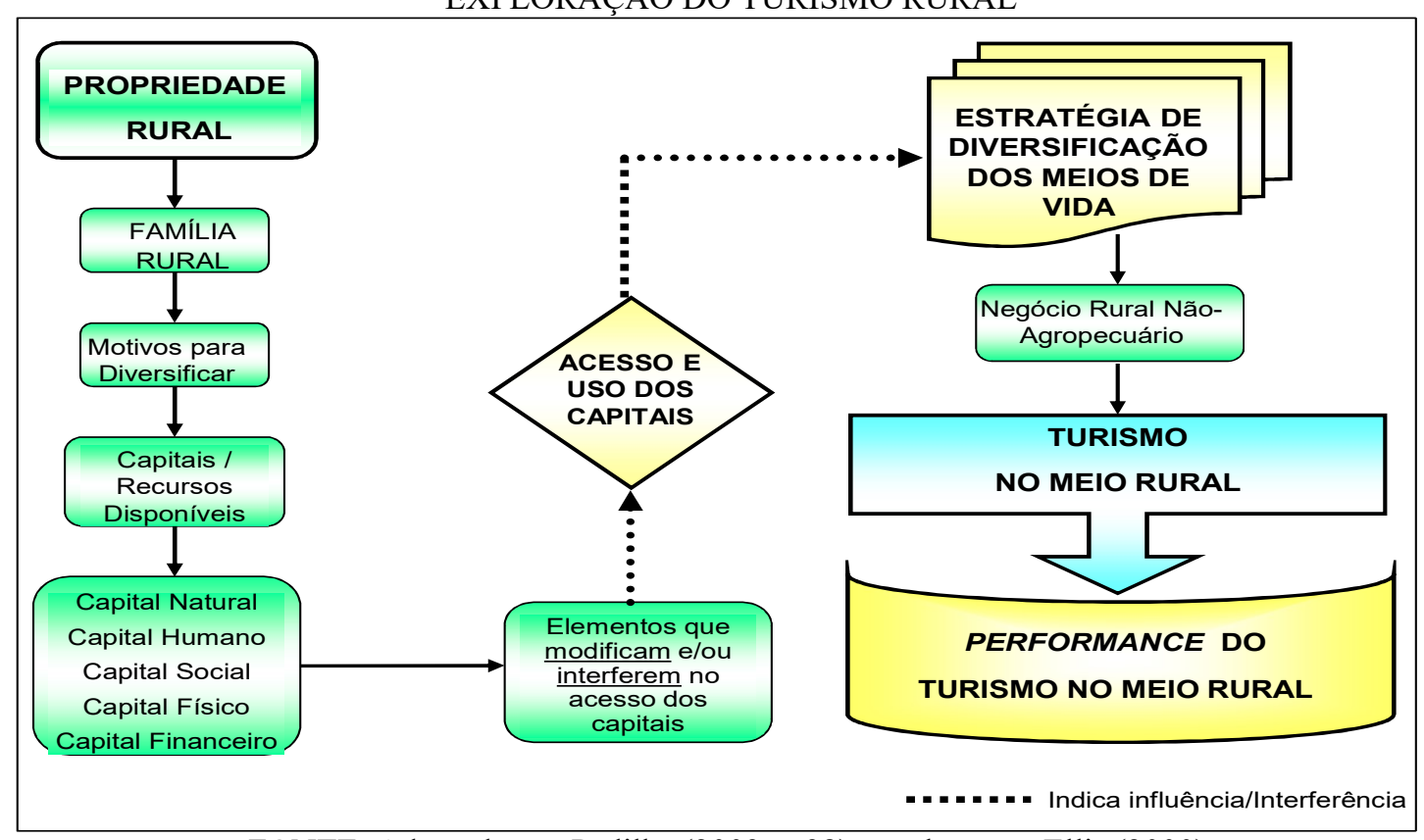

FONTE: Adaptado por Padilha (2009, p.98) com base em Ellis (2000).

A estratégia de diversificação dos meios de sustento pode sofrer interferência ou modificação do acesso que o indivíduo ou unidade familiar possui à plataforma de sustento, explicado pelos fatores endógenos e exógenos (ELLIS, 2000). Os endógenos têm o papel de modificar o acesso aos capitais e são especificados pelas normas sociais e 
estruturas das quais as unidades familiares e os indivíduos fazem parte (relações sociais, instituições e organizações). Os exógenos são identificados pelas tendências (população, migração, tecnologia agrícola e a sua evolução, crescimento de atividades não ligadas ao campo em áreas rurais, preços, cenários econômicos nacionais e internacionais, políticas e tendências macroeconômicas) e choques (eventos como enchentes, secas, pestes, epidemias e guerras civis - podem destruir os ativos diretamente ou causar indiretamente sua erosão. Em qualquer dos casos, os fatores provocarão uma necessidade imediata de mudança na estratégia de sustento para o indivíduo ou para o meio social no qual está inserido, dependendo do escopo do efeito do choque.

Com relação ao turismo, os efeitos ou performance dessa atividade nos meios de subsistência (MBAIWA, 2011; QIAN et al., 2017; SHOO; SONGORWA, 2013) podem apresentar influência positiva na renda e emprego (HERNANDEZ CRUZ et al., 2005; HUNT et al., 2015; WISHITEMI et al., 2015), educação, habilidades e criação de pequenas empresas (WISHITEMI et al., 2015). Na perspectiva econômica, sublinha-se o crescimento da atividade empresarial empreendedora de médios e pequenos produtores rurais, crescimento do investimento de capital (privado e público), revalorização de recursos não econômicos (transformação em recursos atrativos turísticos), empoderamento, desenvolvimento regional, cooperação inter-regional e crescimento do padrão de vida da população local (RUZIC; DEMONJA, 2017).

A performance da estratégia de diversificação de sustento rural a partir da exploração do turismo rural (Figura 1), também pode ser evidenciada pelos outputs comerciais (produtos e serviços) e os outputs de conhecimento (criatividade e inovação). Os outputs se aliam à permanência das famílias no meio rural, ampliação da segurança de seu sustento, resgate de tradições familiares e locais, desenvolvimento local, contato com pessoas a comunidade e turistas, preservação ambiental, revalorização do rural, geração de postos de trabalho e, especialmente, o fortalecimento do setor e reconhecimento nacional (PADILHA et al., 2017; PADILHA et al., 2019).

\section{PROCEDIMENTOS METODOLÓGICOS}

A partir do delineamento do objetivo do estudo, a pesquisa utilizou uma abordagem qualitativa por não ter a preocupação com a representatividade numérica, mas, sim, com o aprofundamento da compreensão de um grupo social (MINAYO, 2001). 
A pesquisa se classifica como descritiva, pois busca descrever as características de determinadas populações ou fenômenos (GIL, 2008). E, como técnica de estudo, elegeuse a de multicaso (YIN, 2005) por proporcionar a investigação de fenômenos contemporâneos dentro do seu contexto de vida real, em situações em que as fronteiras entre o fenômeno e o contexto não estão claramente estabelecidas, nas quais se utilizam múltiplas fontes de evidência.

Conforme mencionado na introdução deste artigo, o objeto da pesquisa foi a Rota das Salamarias localizada no município de Marau, Rio Grande do Sul. O município integra a região Planalto Médio, com área de aproximadamente $650 \mathrm{Km}^{2}$, população predominante de origem italiana, possuindo cerca de 40 mil habitantes (FEE, 2015), sendo que desta população, estima-se que 2.600 famílias vivem na zona rural produzindo grãos, leite, aves e suínos (PREFEITURA MUNICIPAL, 2017).

Para a coleta de dados foram selecionados três empreendimentos rurais de turismo a partir dos critérios: (a) famílias rurais que exploram atividades agropecuárias e o turismo concomitantemente; (b) performance no turismo em termos de ampliação do nível de sustento, motivação para permanecer no meio rural e desenvolvimento de novos produtos, serviços e atrativos;(c) destinam recursos financeiros, aplicam técnicas e de planejamento no turismo rural; (d) demonstraram interesse em participar da pesquisa.

Os dados primários foram coletados por meio de um roteiro de entrevistas realizadas nos meses de julho a novembro de 2016 com os proprietários das unidades de produção que são os responsáveis pelas decisões de diversificação, sendo o instrumento de pesquisa integrado pelas seguintes partes: (a) identificação e inserção da propriedade rural; (b) implantação da atividade turística; (c) diversificação dos meios de subsistência; (d) acesso e uso dos capitais; e (e) elementos que modificam ou interferem no acesso aos capitais. Os dados secundários foram obtidos da literatura consultada e sites da internet que possuíam elementos e informações oficiais.

Para a análise dos dados as propriedades foram caracterizadas por meio de letras $(\mathrm{A}, \mathrm{B}, \mathrm{C})$ para proteger a identidade dos participantes da pesquisa. A técnica de análise dos dados selecionada foi a análise de conteúdo das entrevistas sugerida por Bardin (1997), considerando as seguintes etapas: (a) pré-análise: organização com o uso de vários procedimentos, tais como a leitura flutuante, as hipóteses, os objetivos e a elaboração de indicadores que fundamentem a interpretação; (b) exploração do material: nessa etapa ocorre a codificação dos dados com base nas unidades de registro; (c) 
tratamento dos resultados e interpretação: classificação dos elementos segundo suas semelhanças e diferenciação, com posterior reagrupamento, em razão de características comuns, como exposto na seção seguinte.

\section{APRESENTAÇÃO E ANÁLISE DOS RESULTADOS}

Esta seção dedica-se à apresentação e análise dos resultados obtidos na pesquisa.

\subsection{A ROTA DAS SALAMARIAS E AS PROPRIEDADES RURAIS PESQUISADAS}

Dentre os setores econômicos do município de Marau, o turismo rural tem ganhado destaque. A população conserva a cultura herdada dos imigrantes italianos, construções históricas, hábitos, cultura e tradição que se alia às paisagens no meio rural. Acidade é reconhecida como a "Capital Nacional do Salame", devido à significativa produção no município que culmina com o principal evento regional que é o "Festival Nacional do Salame".

Da união de famílias rurais que despertaram o interesse em empreender e ampliar suas atividades a partir da exploração do turismo rural, em junho de 2008 cria-se a Associação Rota das Salamarias, integrada por 13 propriedades rurais. Conforme ilustrado na Figura 2, os atrativos incluem trilhas ecológicas, degustações de produtos como cachaças, vinhos, licores, gastronomia italiana, salames e hospitalidade das famílias rurais (SALAMARIAS, 2016). 
FIGURA 2: ILUSTRAÇÃO DA ROTA DAS SALAMARIAS.

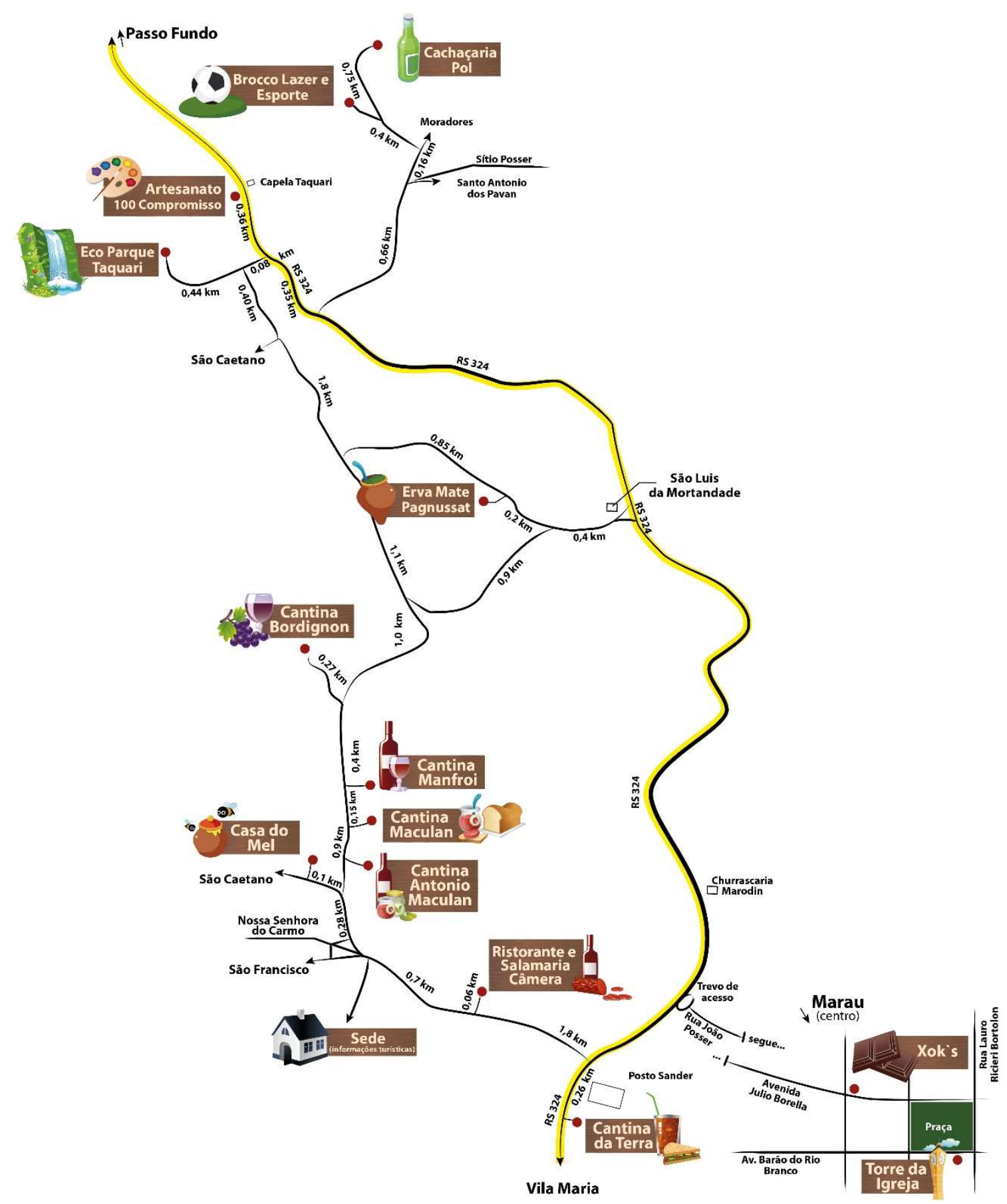

FONTE: Salamarias (2019).

Fundada em 2009, a Propriedade A é administrada por uma família rural integrada por seis membros. Possui uma área total de 26 ha. Desta área, 1,5ha destina-se à oferta do turismo rural e, o restante, 24,5ha, destina-se à produção de grãos (soja, milho 
e trigo). Também possui uma agroindústria familiar para produção de derivados de suínos (salame, pernil, copa, torresmo e banha) que são comercializados na propriedade.

A diversificação e atuação no turismo deram-se a partir da criação da Rota das Salamarias que viabilizou a comercialização dos embutidos. Pensando em aumentar a renda da família, no ano de 2009 foi inaugurada uma infraestrutura com arquitetura sustentável. Nesse espaço é oferecido aos turistas: almoço, jantar, café típico italiano e visitação no museu de antiguidades. De acordo com o relato do proprietário:

Só a renda de uma das atividades, teríamos mais dificuldades de sobrevivência, pois não seria o suficiente para manter toda a família. Com o incentivo da Prefeitura Municipal, tivemos a oportunidade de fazer parte do roteiro turístico que hoje participa com $40 \%$ das nossas receitas.

Quanto à capacidade, adequação e qualidade nas instalações, o restaurante pode receber até 90 pessoas. Conforme revelou o proprietário, o público frequentador das atividades turísticas origina-se das cidades próximas, geralmente famílias, terceira idade e grupos escolares.

A Propriedade B é administrada pelo patriarca e quatro membros da família. A propriedade possui uma área total de 15 ha, sendo que 3,5 ha são utilizados para o cultivo de uva (produção do vinho), 5 ha para a produção leiteira e 6,5 ha para a produção de grãos.De acordo com o entrevistado, a propriedade tem como atrativo a produção e degustação de licores e vinhos, revelando que:

A produção de licores e de vinhos é feita há aproximadamente 50 anos, que foi iniciada pelo meu pai. Por isso resolvi continuar com a tradição, sendo que hoje produzo mais de $6000 \mathrm{mil} /$ litros de vinhos por ano (...) buscamos sempre inovar e trazer novidades na fabricação de vinhos e licores.

A exploração do turismo deu-se em razão das atuais atividades agrícolas não gerarem mais o sustento para a família rural. A disponibilidade da mão de obra familiar foi um elemento importante na opção pelo turismo. Segundo o entrevistado:

Cada pessoa tem uma tarefa diferenciada e destinada. Alguns ficam com a plantação de soja, outros ficam com o gado leiteiro e eu faço toda a parte da produção do vinho. Antigamente, quem fazia todo este trabalho, e muito mais manualmente que hoje, era meu pai.

$\mathrm{Na}$ análise da infraestrutura, tem capacidade para atender 50 pessoas. Esse aspecto é importante no que se refere à qualidade e satisfação dos turistas que buscam este tipo de atrativo. Outro aspecto que chamou atenção no relato do proprietário 
relaciona-se ao reconhecimento, ou seja, seu trabalho foi valorizado a partir do momento em que se integrou à Rota das Salamarias. Além disso, a valorização externalizada pelo público frequentador motivou o investimento em benfeitorias e melhoria no processo de fabricação dos produtos que comercializa na rota turística.

A Propriedade $\mathbf{C}$ também é familiar e produz erva-mate há 47 anos de forma artesanal. Ela possui uma área de 37 ha, sendo 20ha destinados à produção agrícola, 10 ha à agropecuária, e 7ha destinadas aos atrativos do turismo, quais sejam: restaurante, matas, trilhas ecológicas e áreas para a prática de esporte.

A principal atividade da família rural é a produção de erva-mate, iniciada no ano de 1964 e comercializada em escala a partir de 1997. Conforme revelou o pesquisado, a produção de erva-mate é uma referência no município de Marau, configurando-se como um atrativo aos visitantes que buscam conhecer o processo de produção. De acordo com o entrevistado, a produção da erva-mate partiu de seu pai, informando:

Eu só continuei o trabalho que meu pai fazia antigamente, e fiz alguns investimentos na propriedade como campos de vôlei e futebol, parque para as crianças e um lugar para eventos, tornando assim um lugar para descanso e lazer. Quero sempre continuar investindo para que fique cada vez melhor.

$\mathrm{Na}$ entrevista realizada, pode-se notar que em termos de geração de renda familiar a produção de erva-mate, que é comercializada no município e aos turistas, tem a maior participação no rendimento global.

\subsection{IMPLANTAÇÃO DA ATIVIDADE DE TURISMO RURAL}

Na entrevista realizada com o proprietário da Propriedade A pode-se notar que a principal motivação para o investimento no turismo respaldou-se na possibilidade de melhoria da qualidade de vida de seus filhos, bem como a opção de fonte adicional de renda com a exploração de espaços ociosos.

Para dar conta da nova atividade, o proprietário recebeu apoio técnico da EmaterRS, e do Poder Público Municipal por meio de oferta de cursos voltados para a qualificação e atualização de informações relacionadas à dinâmica da oferta do serviço de turismo rural.

Quanto aos recursos financeiros para investimento em infraestrutura, 70\% originaram-se de recursos próprios e 30\% foram obtidos de instituições financeiras, em 
que os aspectos relacionados à decisão são questões de difícil projeção e que podem extrapolar o orçamento projeto. Nesse sentido, o entrevistado mencionou:

Quando achamos que tínhamos o valor suficiente para a obra, nos enganamos
(..) sempre gastamos mais do que planejamos, sempre vai haver algum
imprevisto que não está no projeto e nem no orçamento. Também procuramos
pesquisar preços para que não extrapolasse o orçamento de investimento
inicial.

Para o proprietário da Propriedade B, a motivação para implantar o turismo deuse pela valorização dos produtos percebidos pelos consumidores que os adquiriam muito antes da decisão de se inserir na atividade. Segundo o proprietário: “A qualidade de um bom vinho se dá da maneira como você o faz".

Com relação aos aspectos negativos ou dificuldades relacionadas à atividade de turismo, o proprietário comentou que o Poder Público Municipal e a Emater poderiam ampliar o apoio, especialmente no que se refere à motivação das famílias que integram a Rota das Salamarias, discutindo novas possibilidades de exploração do potencial rural e produção artesanal.

Na terceira propriedade pesquisada, a Propriedade C, os dados coletados com o proprietário revelaram que a principal motivação na implantação da atividade turística foi a ampliação das fontes de renda no meio rural.

No que se refere ao apoio técnico recebido, ele também destacou a Prefeitura Municipal e a Emater. Nota-se que estes dois atores tiveram papel importante na instalação da Rota das Salamarias e assessoria aos produtores rurais no momento de se ofertar atrativos de turismo rural.

Outro aspecto identificado na pesquisa relaciona-se aos recursos financeiros que viabilizaram o turismo rural. Segundo o pesquisado, o investimento total originou-se de recursos próprios e poupança pessoal, não sendo identificada a captação de recursos de terceiros ou de instituições financeiras.

$\mathrm{Na}$ dimensão das dificuldades relacionadas ao turismo, o entrevistado mencionou a gestão da mão de obra contratada, uma vez que existe a limitação de atuação em determinados dias da semana (finais de semana) e horários (noturno). 


\subsection{DADOS REFERENTES À OCUPAÇÃO DA MÃO DE OBRA}

Conforme evidenciado na maioria dos setores da economia brasileira, a mão de obra configura-se como um dos principais entraves de desenvolvimento. De acordo com Perondi (2007) a agricultura familiar é conduzida pela força de trabalho da própria família ou do grupo doméstico, estruturada em torno de laços sanguíneos e de parentesco entre seus membros.

Analisando-se esta categoria, na Propriedade Aas atividades agropecuárias e de turismo são desenvolvidas pela família rural, que é integrada por seis membros e, também, pela mão de obra contratada. Com relação à mão de obra familiar, o entrevistado mencionou:

A importância da mão-de-obra familiar na nossa atividade tem grau elevado, pois o turista sente-se mais confiante com o atendimento de nossa família. Ele sente uma sensação de aconchego, pois relembra muito o passado das famílias que se reuniam para confraternizar com os momentos na casa da "nona".

Apenas no turismo é utilizada a mão de obra contratada, que se dedicada à elaboração das refeições. A contratação dá-se pela indicação de amigos ou vizinhos e experiência dos candidatos na função.

Já na Propriedade $\mathbf{B}$ foi possível identificar que em todas as suas atividades emprega-se somente a mão de obra familiar, num total de cinco pessoas, sendo elas: o próprio entrevistado que é o patriarca da família, sua esposa, seus dois filhos e uma nora. Nessa configuração, a nora é a responsável pela produção leiteira e, seus dois filhos, responsáveis pelo turismo.

No que se refere à qualificação dos membros da família rural, o entrevistado mencionou a carência ou ausência de cursos específicos para a qualificação de mão de obra para atuar no meio rural, principalmente os relacionados às atividades de turismo. Isso parece ser um aspecto importante quando se analisa novas alternativas de geração de renda no meio rural, as quais podem ser ou não diversificadas. Quanto ao turismo, conhecimento de mercado, inovação, gestão, produção, entre outros aspectos, podem contribuir para a sobrevivência destes pequenos empreendimentos e permanência das famílias no meio rural.

Conforme relatado anteriormente pelo proprietário da Propriedade $\mathbf{C}$, a oferta de mão de obra para atuar no meio rural é um dos fatores que limitam, em determinados 
momentos, a qualidade do serviço de turismo ofertado. No entanto, existe uma preocupação contínua de seus membros em observarem, visitarem, conhecerem empreendimentos de turismo rural com o intuito de realizar benchmarking, ou seja, uma avaliação constante da oferta das empresas do mesmo ramo.

\subsection{DADOS DA FORMAÇÃO E COMPOSIÇÃO DA RENDA}

Outro aspecto investigado relaciona-se à origem da renda das atividades diversificadas das propriedades pesquisadas (Tabela 1).

TABELA 1: DADOS DA FORMAÇÃO E COMPOSIÇÃO DA RENDA (EM \%).

\begin{tabular}{c|l|c}
\hline Propriedades & \multicolumn{1}{|c}{ Atividades desenvolvidas } & Renda(\%) \\
\hline \multirow{2}{*}{ A } & Produção de grãos & 60 \\
\cline { 2 - 3 } & Turismo (restaurante) & 40 \\
\hline \multirow{3}{*}{ B } & Produção de grãos & 10 \\
\cline { 2 - 3 } & Produção de leite & 50 \\
\cline { 2 - 3 } & Turismo (degustação de vinhos e licores) & 40 \\
\hline \multirow{2}{*}{ C } & Produção de grãos & 30 \\
\cline { 2 - 3 } & Turismo (refeições, passeios, comercialização erva-mate) & 70 \\
\hline
\end{tabular}

FONTE: Dados do estudo (2016).

A atividade de produção de grãos na Propriedade A supera, relativamente, a de turismo. Já na Propriedade B, a renda derivada da produção de leite supera a produção de grãos, seguida da renda auferida do turismo rural. E quanto à Propriedade $\mathbf{C}$, a maior participação na composição da renda é explicada pelo turismo (70\%), seguida da produção de grãos $(30 \%)$.

Dessa forma, o desenvolvimento de mecanismos que possibilitem a geração de renda adicional, derivados de novas oportunidades de negócios explicados pelas escalas de produção, especialização, diferenciação de processos produtivos e de produtos, agregação de valor, entre outros, podem contribuir no enfrentamento das mudanças que afetam as unidades produtivas.

\subsection{GESTÃO ADMINISTRATIVA, FINANCEIRA, ASSISTÊNCIA TÉCNICA E DIVULGAÇÃO}

Um elemento importante da diversificação de sustento de pequenas propriedades no meio rural é a gestão, a administração financeira a assistência técnica e a divulgação. 
O Quadro 2 resume os dados coletados nas entrevistas com os proprietários pesquisados acerca destes temas.

QUADRO 2 - GESTÃO ADMINISTRATIVA, FINANCEIRA, ASSISTÊNCIA TÉCNICA E DIVULGAÇÃO

\begin{tabular}{|c|c|c|c|c|}
\hline Propriedade & \begin{tabular}{|c|} 
Gestão \\
Administrativa
\end{tabular} & Gestão Financeira & \begin{tabular}{|c|} 
Assistência \\
Técnica \\
\end{tabular} & Divulgação \\
\hline $\mathbf{A}$ & \begin{tabular}{|c|} 
Decisões em \\
consenso com os \\
membros da \\
família.
\end{tabular} & $\begin{array}{l}\text { Preocupação com investimentos } \\
\text { e aquisições. } \\
\text { Fixação de preços de acordo com } \\
\text { o mercado. }\end{array}$ & Emater & $\begin{array}{c}\text { Festival Nacional do } \\
\text { Salame. } \\
\text { Página em rede social. } \\
\text { Reportagens de TV local. } \\
\text { Jornais locais. }\end{array}$ \\
\hline B & $\begin{array}{l}\text { Decide com os } \\
\text { filhos. }\end{array}$ & $\begin{array}{c}\text { Importante para negócios } \\
\text { diversificados. } \\
\text { Influencia no capital de giro. } \\
\text { Preços calculados com base em } \\
\text { estoques de matéria-prima, mão } \\
\text { de obra e lucro. } \\
\end{array}$ & Emater & $\begin{array}{l}\text { Participação em } \\
\text { exposições no município. } \\
\text { Festival Nacional do } \\
\text { Salame. }\end{array}$ \\
\hline C & $\begin{array}{c}\text { Não } \\
\text { identificado. }\end{array}$ & $\begin{array}{c}\text { Não possui fluxo de caixa } \\
\text { (controles). } \\
\text { Não tem controle de receitas e } \\
\text { despesas. }\end{array}$ & Emater & $\begin{array}{l}\text { "Boca-a-boca". } \\
\text { Festival Nacional do } \\
\text { Salame. }\end{array}$ \\
\hline
\end{tabular}

FONTE: Dados do estudo (2016).

Analisando o Quadro 2 nota-se que a complexidade nomeio rural é uma realidade, especialmente quando analisadas as decisões financeiras relacionadas às prioridades de investimento. Por se tratar de atividades diversificadas que incluem as agropecuárias, é possível que as escolhas as priorizem, tendo em vista a demanda de mercado e preços pagos pelos produtos agropecuários, podendo influenciar os investimentos financeiros dedicados ao turismo, geralmente desenvolvido como uma atividade complementar no meio rural. Com relação a isso, percebe-se uma exigência de esforços dos gestores na direção da viabilização dos negócios e alcance de um nível de sustento adequado ou um padrão competitivo que seja auto-sustentável. Nesse aspecto, sublinha-se a necessidade de uma participação efetiva e eficaz de instituições de apoio que ofereçam suporte para este tipo de empreendimento no meio rural.

\subsection{DIVERSIFICAÇÃO DOS MEIOS DE SUSTENTO}

Tomando-se como base os dados coletados nas entrevistas com os três proprietários das unidades de produção familiar, pode-se notar que na Propriedade A, a diversificação dos meios de sustento por meio do turismo rural partiu do consenso de seus membros. Na Propriedade B, a ideia foi do patriarca da família, assim como, na 
Propriedade C. Um aspecto relevante que facilitou o desenvolvimento do turismo neste município foi a motivação dos integrantes da Rota, a união e o empenho do grupo para a concretização da Rota das Salamarias.

a) Acesso e uso da plataforma de sustento

Os capitais acessados e explorados, explicados pela plataforma de sustento (ELLIS 1999; 2000), revelam-se como fatores imprescindíveis para que a família rural mude sua estratégia de sustento ao diversificar suas atividades ligadas ao meio rural (PADILHA, 2009; PADILHA et al., 2017).

A viabilização de uma estratégia de diversificação em qualquer tipo de empreendimento necessita, sobremaneira, mobilizar recursos ou capitais para sua concretização e sucesso (Quadro 3), especialmente, no contexto do turismo rural.

De acordo com a entrevista realizada com o proprietário da Propriedade A, foram identificadas as estradas de acesso como um capital importante, destacando: “Apesar do asfalto estar sendo construído no início da Rota, até ele chegar à propriedade irá demorar mais alguns anos e, enquanto isso, perdemos muitos turistas em função desta precariedade". Nesse mesmo contexto, a Propriedade B e a Propriedade C compartilham da mesma percepção.

Também foram investigados os elementos que modificam o acesso aos capitais que, de acordo com Ellis (2000), quanto maior for o acesso aos capitais, maior será a capacidade de sustento do indivíduo. Nessa análise, os proprietários da Propriedade A e da Propriedade $\mathbf{C}$ não identificaram fatores que pudessem interferir ou modificar o acesso aos capitais. Quanto à Propriedade B, o pesquisado mencionou que o excesso de chuva em determinados períodos do ano acaba inviabilizando o acesso dos turistas à sua propriedade, bem como a falta de linhas de crédito específicas para o turismo rural. 


\section{QUADRO 3: CAPITAIS UTILIZADOS NA ESTRATÉGIA DE DIVERSIFICAÇÃO DE SUSTENTO RURAL.}

\begin{tabular}{|c|c|c|}
\hline Capitais & Propriedades & Acesso e uso dos Capitais \\
\hline \multirow{3}{*}{ Natural } & A & $\begin{array}{l}\text { - Fonte d'água. } \\
\text { - Reservatório (lago). }\end{array}$ \\
\hline & B & $\begin{array}{l}\text { - Fontes d'água. } \\
\text { - Solo fértil. }\end{array}$ \\
\hline & $\mathrm{C}$ & - Mata nativa \\
\hline \multirow{3}{*}{ Físico } & A & $\begin{array}{l}\text { - Máquinas e equipamentos (produção grãos) } \\
\text { - Infraestrutura (refeições) }\end{array}$ \\
\hline & $\mathrm{B}$ & - Máquinas e equipamentos (colheita da uva) \\
\hline & $\mathrm{C}$ & - Máquinas e equipamentos (produção erva-mate) \\
\hline \multirow{3}{*}{ Humano } & A & $\begin{array}{l}\text { - Mão de obra familiar. } \\
\text { - Mão de obra contratada (restaurante). }\end{array}$ \\
\hline & $\mathrm{B}$ & - Mão de obra familiar. \\
\hline & $\mathrm{C}$ & - Mão de obra familiar. \\
\hline \multirow{3}{*}{ Financeiro } & A & - Linhas de crédito para investimento em infraestrutura. \\
\hline & $\mathrm{B}$ & - Linhas de crédito para produção de grãos. \\
\hline & $\mathrm{C}$ & - Capital próprio em baixa escala. \\
\hline \multirow{3}{*}{ Social } & A & $\begin{array}{l}\text { - Comunidade. } \\
\text { - Vizinhos. } \\
\text { - Festival Nacional do Salame. }\end{array}$ \\
\hline & B & $\begin{array}{l}\text { - Comunidade. } \\
\text { - Vizinhos. } \\
\text { - Festival Nacional do Salame. }\end{array}$ \\
\hline & $\mathrm{C}$ & $\begin{array}{l}\text { - Comunidade. } \\
\text { - Vizinhos. } \\
\text { - Festival Nacional do Salame. }\end{array}$ \\
\hline
\end{tabular}

FONTE: Dados do estudo (2016).

Outro aspecto pesquisado relaciona-se aos elementos que interferem no acesso aos capitais. Segundo Ellis (2000), uma característica fundamental das famílias rurais nos países em desenvolvimento é a habilidade de se adaptarem ao objetivo de sobreviver. O proprietário da Propriedade A não soube informar sobre os elementos que interferem ao acesso aos capitais. Na Propriedade B, o entrevistado relatou que um dos fatores é a tecnologia das máquinas para a produção que estão no mercado. O pesquisado da Propriedade $\mathbf{C}$ destacou como elemento que interfere no acesso ao capital físico o preço de mercado de máquinas modernas que dinamizariam o processo de produção da de ervamate.

Entre os fatores exógenos ainda se encontram os choques externos. Para Ellis (2000), esses fatores representam uma mudança particular na sustentabilidade dos meios de sustento. Segundo o proprietário da Propriedade A, a produção de grãos é suscetível à ocorrência de pragas, secas, excesso de chuvas que podem influenciar negativamente a produtividade e qualidade do produto, além do preço de venda que é regulado pelo 
mercado internacional. Por se tratar de uma unidade de produção familiar que possui as atividades agropecuárias como o principal meio de sustento, o turismo ocupa uma posição de atividade complementar, sendo que na maioria das vezes, os investimentos para a atividade provêm do capital financeiro auferido da agropecuária. Deduz-se que, se a performance destas atividades não alcança um nível adequado, o turismo pode sofrer limitações em termos de investimentos.

O pesquisado da Propriedade B mencionou a influência do clima no cultivo das videiras, especialmente em períodos de estiagem que interferem negativamente na qualidade das uvas e, por consequência, na produção de vinhos. Nesse caso, a capacidade de manter uma produção uniforme ao longo do ano poderá influenciar negativamente na demanda turística e, por consequência, na manutenção do sustento familiar.

$\mathrm{Na}$ percepção do pesquisado da Propriedade C, a ocorrência de chuvas torrenciais ou vendavais no momento em que os ervais estão em fase de crescimento constitui-se como uma ameaça na produção da erva-mate que é o principal atrativo turístico da propriedade. Não somente isso, o fato dos empreendimentos se localizarem no meio rural, em determinadas épocas do ano, a demanda é limitada pela dificuldade de acesso dos turistas em razão da péssima qualidade das estradas.

A partir destas considerações, a Figura 3 resume os elementos do estudo. Ao se observar a performance da estratégia de diversificação de sustento rural, nota-se que o acesso e uso dos cinco capitais são fundamentais para o sucesso da estratégia, o que culmina na geração e alcance de um nível de sustento seguro (ELLIS, 2000). É importante mencionar as dimensões imateriais que parecem estar envolvidas na diversificação dos meios de sustento rural a partir da exploração do turismo. Elas perpassam os aspectos econômicos, uma vez que o contato com turistas, o embelezamento das propriedades rurais, o interesse em compartilhar a história, costumes e culinária. As dimensões imateriais também integram a performance da diversificação, revelando-se como um dos aspectos mais importantes que contribui para a sucessão familiar e permanência das famílias nestes espaços geográficos. 
FIGURA 3 - RESULTADOS DA ESTRATÉGIA DE DIVERSIFICAÇÃO DOS MEIOS DE VIDA A PARTIR DA EXPLORAÇÃO DO TURISMO RURAL

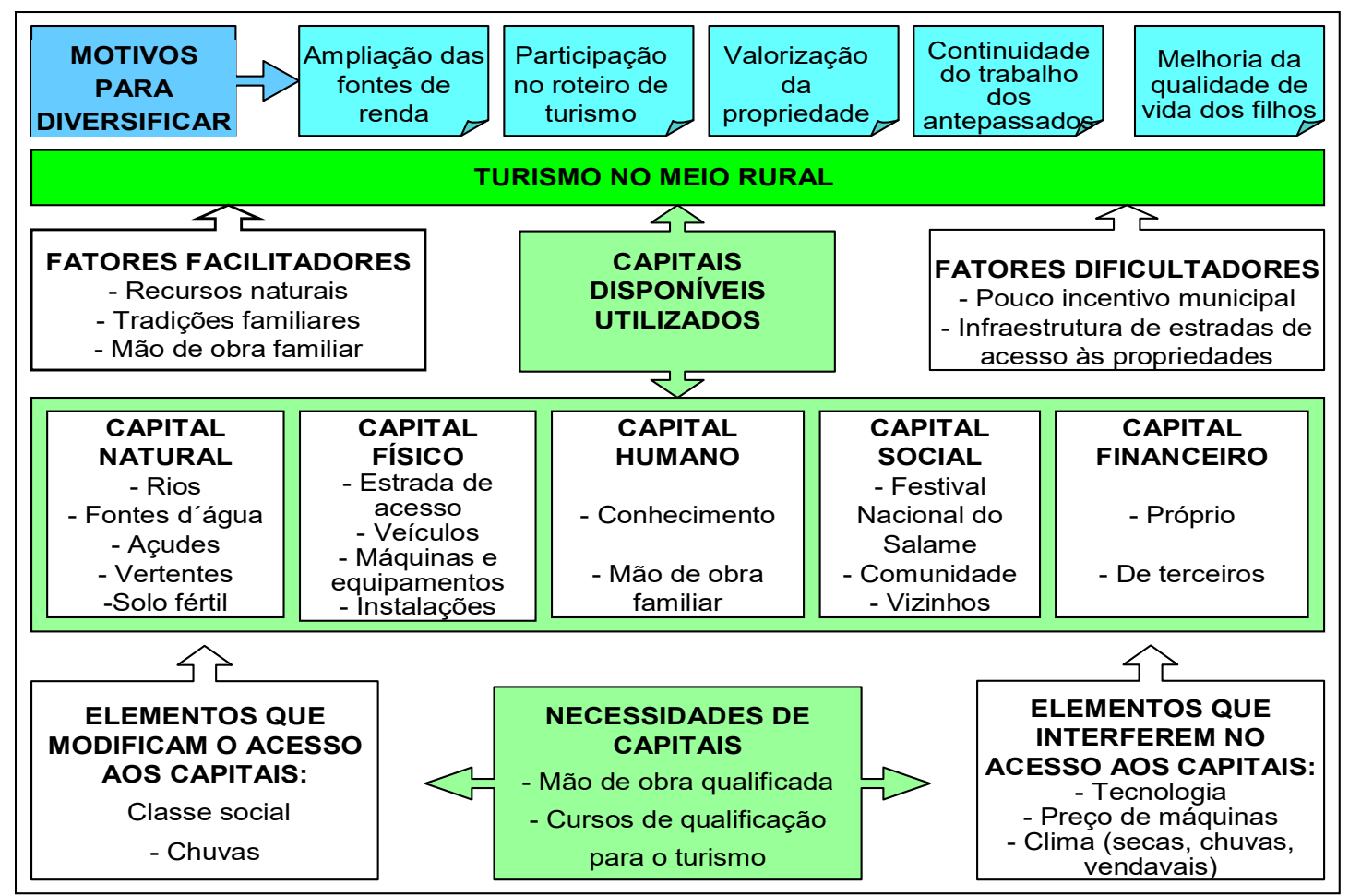

FONTE: Dados do estudo (2016).

\section{CONSIDERAÇÕES FINAIS}

A pesquisa buscou identificar a estratégia de diversificação dos meios de vida de produtores rurais que exploram o turismo na Rota das Salamarias de Marau (RS). Nesse aspecto, foi possível perceber que não somente a Rota tem alcançado relativa projeção no turismo, mas, também, que a região vem se destacando por este tipo de iniciativas empreendidas nas unidades de produção familiar. Isto contribui decisivamente para a ampliação da segurança do sustento, conservação da cultura, tradição e culinária típica, bem como a preservação dos recursos naturais existentes.

Adicionalmente, foi possível analisar no roteiro selecionado alguns aspectos que induzem o desenvolvimento do turismo rural em roteiros turísticos, especialmente quando se observa o acesso que as famílias rurais têm à plataforma de sustento ou capitais.

Em se tratando de apoio para o desenvolvimento do turismo rural, um gargalo relaciona-se ao apoio para o setor. O desenvolvimento socioeconômico de qualquer setor depende de informações básicas para permitir o planejamento adequado das estratégias 
que cada associação ou unidade de produção familiar, as quais contribuem para novas proposições, prioridades, ações e escolhas de geração de renda e permanência no meio rural.

Foi possível identificar a falta de políticas públicas para o desenvolvimento do turismo rural, bem como a participação mais efetiva das demais instituições de apoio. Padilha (2009) considera que, como não poderia ser diferente de outros setores do agronegócio, de certa forma, a falta de políticas governamentais específicas de fomento e desenvolvimento do turismo rural vem, ao longo do tempo, pressionando negativamente propriedades rurais que não alcançaram um padrão competitivo, especialmente quando observada a produção agropecuária. A isso se adiciona a análise de cadeias produtivas para o entendimento de como cada agente pode se comportar diante da necessidade de organização estratégica que fortaleça o desenvolvimento do turismo rural.

Por se tratar de uma rota turística os resultados também contribuíram para um entendimento de que, cada vez mais, a tendência de se estabelecerem estratégias de cooperação com o propósito de desenvolvimento parece ser uma escolha viável que ganha espaço neste tipo de configuração. Portanto, arranjos cooperativos com participação efetiva de stakeholders parecem ser um padrão possível de adoção no setor de turismo rural, especialmente em regiões menos desenvolvidas que apresentam potencial para a criação deste tipo de atrativo.

Quanto aos reflexos do desenvolvimento do turismo rural, quando bem organizado, pode não só viabilizar a permanência no meio rural, mas, sobretudo, desenvolver econômica e socialmente a comunidade. Umas das principais características do turismo rural em estágios avançados de desenvolvimento é o poder de fortalecer a economia regional, integrando desde a prestação de serviços, passando pelo suprimento de bens, até o desenvolvimento social. Este último pode ser representado, especialmente, pela produção de artesanato que imprime no resultado final traços da cultura local.

Ao se reportar aos procedimentos metodológicos empregados para o desenvolvimento da pesquisa, ressalta a não generalização das conclusões. A pesquisa também apresenta limitação na etapa empírica, especialmente quando se observa a performance da estratégia de diversificação do sustento rural respalda-se no fato da indisponibilidade para análise acurada das informações contábeis dos negócios diversificados. Esta limitação talvez indique um espaço concreto de pesquisa futura principalmente nas regiões que se envolvem historicamente com o turismo rural que se 
situam em espaços geograficamente privilegiados com diversidade de capitais que podem ser explorados no contexto do turismo.

\section{REFERÊNCIAS}

ANNES, A.; BESSIERE, J. Staging agriculture during on-farm markets: How does French farmers' rationality influence their representation of rurality? Journal of Rural Studies, v.63, p.34-45, 2018.

BARDIN, L. Análise de conteúdo. Lisboa: Edições 70, 1997.

BARRETT, C. B.; REARDON, T.; WEBB, P. Nonfarm income diversification and household livelihood strategies in rural Africa: concepts, dynamics, and policy implications. Food Policy, v.6, n.4, p.315-331, 2001.

BUSBY, G.; RENDLE, S. The transition from tourism on farms to farm tourism. Tourism Management, v.2, n.6, p.635-642, 2000.

DUBOIS, C.; SCHMITZ, S. Le tourisme à La ferme: une expérience authentique ou um simulacre.In Decroly, J.-M. (Ed.), Le tourisme comme experience: Regards interdisciplinaires sur le vécu touristique. Presses del'Universitédu Québec, Québec, 2015.

ELLIS, F. Household strategies and rural livelihood diversification. The Journal of Development Studies, v.35, n.1, p.1-38, 1998.

ELLIS, F. Rural livelihoods and diversity in developing countries. Oxford: Oxford University Press, 2000.

ELLIS, F.; BIGGS, S. Evolving Themes in Rural Development 1950s-2000s.

Development Policy Review, v.19, n.4, p.437-448, 2001.

FUNDAÇÃO DE ECONOMIA E ESTATÍSTICA (FEE). Estimativa da população por município, faixa etária e sexo, 2015 - Rio Grande do Sul. Disponível em $<$ http://www.fee.rs.gov.br/indicadores/populacao/estimativas-populacionais/>. Acesso em: 27ago. 2017.

GAUTAM, Y; ANDERSEN, P. Rural livelihood diversification and household wellbeing: Insights from Humla, Nepal. Journal of Rural Studies, v.44, p. 239-249, 2016.

GIL, A. C. Métodos e técnicas de pesquisa social. São Paulo: Atlas, 2008.

HERNANDEZ CRUZ, R. E.; BELLO BALTAZAR, E.; MONTOYA GOMEZ, G.; ESTRADA LUGO, E. I. J. Social adaptation: ecotourism in the Lacandon forest. Annals of Tourism Research, v.32, n.3, p.610-627, 2005. 
HUNT, C. A.; DURHAM, W. H.; DRISCOLL, L.; HONEY, M. Can ecotourism deliver real economic, social, and environmental benefits? A study of the Osa Peninsula, Costa Rica. Journal of Sustainable Tourism, v.23, n.3, p.339-357, 2015.

MBAIWA, J. E. Changes on traditional livelihood activities and lifestyles caused by tourism development in the Okavango Delta, Botswana. Tourism Management, v.32, n.5, p.1050-1060, 2011.

McGEHEE, N.G., KIM, K.; JENNINGS, G. R. Gender and motivation for agri-tourism entrepreneurship. Tourism Management, v.28, n.1, p.280-289, 2007.

McNALLY, S. Farm diversification in England and Wales: what can we learn from the farm business survey? Journal of Rural Studies, v.17, n.2, n.17, p.247-257, 2001.

NICKERSON, BLACK, R.; McCOOL, S. Agritourism motivations behind farm/ranch business diversification. Tourism Management, v.40, n.2, p.19-26, 2001.

MINAYO, M. C. S. O desafio do conhecimento: Pesquisa Qualitativa em Saúde São Paulo: São Paulo: Hucitec-Abrasco, 1992.

NIEHOF, A. The significance of diversification for rural livelihood systems. Food Policy, v.29, n.4, 2004.

OLIVEIRA, I. D.; DINIZ, F. Turismo e Desenvolvimento Regional - Uma perspectiva do Turismo em Espaço Rural na Serra do Marão, em Portugal. Turismo e Sociedade. Curitiba, v.11, n.1, p.113-127, 2018.

PADILHA, A. C. M. A estratégia de diversificação de sustento rural e a dinâmica da capacidade absortiva no contexto do turismo rural: proposição de estrutura de análise. 2009. 257 f. Tese (Doutorado em Agronegócios). Programa de Pós-Graduação em Agronegócios, Universidade Federal do Rio Grande do Sul, Porto Alegre.

PADILHA, A. C. M., SILVA, T. N., SOUZA, M.; HOFF, D. N. A estratégia de diversificação do meio de vida rural e a dinâmica da capacidade de absorção no contexto do turismo rural: proposta de estrutura de análise. Proceedings Book - IX International Tourism Congress, Peniche, Portugal, 2017.

PADILHA, A. C. M.; SOUZA, M.; SECCHI, M.; PELLEGRINI, M.; FRITZ FILHO, L. F. Evidence of the Strategy of Livelihood Diversification in Rural Areas: the Case of the Vale do Paraíso Tourism Route, Brazil. Proceedings Book - XI International Tourism Congress, Madeira Island, Portugal, 2019.

PERONDI, M. A. Diversificação dos meios de vida e mercantilização da agricultura familiar. 2007. 210 p. Tese (Doutorado em Desenvolvimento Rural) - Universidade Federal do Rio Grande do Sul, Porto Alegre, 2007.

PREFEITURA MUNICIPAL DE MARAU. Dados do Município. Disponível em: $<$ http://www. http://www.pmmarau.com.br/sobre-o-municipio/aspectos-gerais $>$. Acesso em: 10 mai. de 2017. 
QIAN, C., SASAKI, N.; JOURDAIN, D.; MINSUN KIM, S.; SHIVAKOTI, G. P. Local livelihood under different governances of tourism development in China - a case study of Huangshan mountain area. Tourism Management, v.61, p.221-233, 2017.

RAMEH, L. M.; SANTOS, M. S. T. Extensão rural e turismo na agricultura familiar: encontros e desencontros no campo pernambucano. Caderno Virtual de Turismo, v.11, n.1, p.49-66, 2011.

REARDON, T. Using evidence of household income diversification to inform study of the rural nonfarm labor market in Africa. World Development, v.25, n.5, p.135-741, 1997.

RUZIC, P.; DEMONJA, D. Economic impacts of rural tourism in rural areas of Istria (Croatia). Transformations in Business \& Economics, v.16, n.3, p.31-40, 2017.

SALAMARIAS. Associação. Disponível em:

$<$ http://www.salamarias.com.br/home/associacao>. Acesso em: 10 out. 2016.

SALAMARIAS. Ilustração da Rota de Salamarias. Disponível em:

$<$ http://www.salamarias.com.br/downloads/mapa_rota_das_salamarias.jpg > . Acesso em: 01 dez. 2019.

SCOONES, I. Sustainable rural livelihoods: a framework for analysis. Working Paper 72. Brighton: Institute for Development Studies, 1998.

SHOO, R. A.; SONGORWA, A. N. Contribution of ecotourism to nature conservation and improvement of livelihoods around Amani nature reserve, Tanzania. Journal of Ecotourism, v.12, n.2, p.75-89, 2013.

WALKER, B.; SALT, D. Resilience Thinking: Sustaining Ecosystems and People in a Changing World. Island Press, Washington, D.C., 2006.

WARREN, P. Livelihoods diversification and enterprise development: an initial exploration of concepts and issues. Food and Agriculture Organization of the United Nations (FAO), Livelihood Support Program (LSP), Working paper 4, Rome, 2002.

WEAVER, D.; FENNELL, D. Rural tourism in Canada: the Saskatchewan Vacation farm operator as entrepreneur. In: PAGE, S. J.; GETZ, D. (Eds.). The business of rural tourism: international perspectives. London: International Thomson Business Press, 1997.

WISHITEMI, B. E. L.; MOMANYI, S. O.; OMBATI, B. G.; OKELLO, M. M. The link between poverty, environmenta and ecotourism development in areas adjacent to Maasai Mara and Amboseli protected areas, Kenya. Tourism Management Perspectives, v.16, p.306-317, 2015. 
WRIGHT, W.; ANNES, A. Farm women and the empowerment potential in valueadded agriculture. Journal of Rural Sociology, v.81, n.4, p.545-57, 2016.

YIN, R. K. Estudo de caso: planejamento e métodos. Porto Alegre: Bookman, 2005.

ZHENG, Y.; BYG, A.; THORSEN, B. J.; STRANGE, N. A temporal dimension of household vulnerability in three rural communities in Lijiang, China. Human Ecology, v.42, n.2, p.283-295, 2014.

Recebido em: 29-07-2019.

Aprovado em: 14-12-2019.

Versão aprovada para publicação em: 16-12-2019. 